\title{
NỒNG ĐÔ GLUCOSE, HbA1c TÁI THỜI ĐIỂM NHẬP VIỆN VÀ MỐI LIỀ̂N QUAN VỚI MỘT SỐ THÔNG SỐ Ở BỆNH NHÂN ĐộT QUỴ NÃO GIAI ĐOẠN CẤP TÍNH
}

\author{
Nguyễn Văn Minh ${ }^{1}$, Hoàng Trung Vinh ${ }^{2}$
}

1. Bệnh viện Trung Vưong - TP Hồ Chí Minh; 2. Học viện Quân y

DOI: $10.47122 / v j d e .2020 .44 .8$

\author{
ABSTRACT \\ Admission blood glucose level and HbAlc \\ and relationship with some parameters in \\ acute stroke patients \\ Nguyen Van Minh ${ }^{1}$, Hoang Trung Vinh ${ }^{2}$ \\ 1. Trung Vuong hospital, HCMC;

\section{Vietnam Military Medical University}

Objectives: To survey admission blood glucose level, HbA1c and relationship with some clinical and subclinical characteristics in acute stroke patients treated in Trung Vuong Hospital, Ho Chi Minh City. Subjects and methods: The participants comprised 98 patients with acute stroke who were performed glucose and HbAlc tests at the time of admission. Increases in blood glucose level and $\mathrm{HbAlc}$ in stroke patients with or without diabetes mellitus was determined as glucose $>$ $6 \mathrm{mmol} / \mathrm{l} ; \mathrm{HbA} 1 \mathrm{c} \geq 5.7 \%$. Results: elevated blood glucose level and $\mathrm{HbAlc}$ accounted for high rates, $84.7 \%$ and $89.6 \%$, respectively. Rate of alone or combined stress hyperglycemia was $20.4 \%$. Female patients had higher rates of increased blood glucose and $\mathrm{HbA1c}$ than male patients. Blood glucose level had a significantly negative correlation with Glasgow Coma Scale. Rate of HbAlc $\geq$ $6.5 \%$ in patients with ischemic stroke was higher than that in those with hemorrhagic stroke. Rates of increased blood glucose and $\mathrm{HbA1c}$ were not significantly associated with previous diabetes diagnosis. Conclusions: Increased blood glucose and $\mathrm{HbAlc}$ occurred in acute stroke patients with high rates, in which stress hyperglycemia did not depend on diabetes mellitus before stroke.

Keywords: stroke; ischemic stroke; hemorrhagic stroke; diabetes mellitus; stress hyperglycemia.

\section{TÓM TẮT}

Mục tiêu: Khảo sát nồng độ glucose, HbA1c máu tại thời điểm nhập viện và mối liên quan với một số đặc điểm lâm sàng, cận lâm sàng ở bệnh nhân đột quỵ não (BN ĐQN) giai đoạn cấp tính điều trị tại bệnh viện Trưng Vương, TP Hồ Chí Minh. Đối tượng và phương pháp: $98 \mathrm{BN}$ ĐQN giai đoạn cấp thuộc đối tượng nghiên cứu được làm xét nghiệm glucose và $\mathrm{HbAlc}$ tại thời điểm nhập viện. Xác định tăng glucose máu và $\mathrm{HbA} 1 \mathrm{c}$ ở $\mathrm{BN}$ ĐQN có hay không có đái tháo đường (ĐTĐ) đều tương ứng với mức: glucose $>6$ mmol/1; HbAlc $\geq 5,7 \%$. Kết quả: Tăng glucose máu và $\mathrm{HbA} 1 \mathrm{c}$ chiếm tỷ lệ cao, tương ứng $84,7 \%$ và $89,6 \%$. Tăng glucose máu phản ứng đơn độc hoặc phối hợp - 20,4\%. Bệnh nhân nữ có tỷ lệ tăng glucose, HbA1c cao hơn so với BN nam. Nồng độ glucose máu tương quan nghịch có ý nghĩa với điểm Glassgow. Tỷ lệ $\mathrm{HbA} 1 \mathrm{c} \geq 6,5 \%$ ở BN nhồi máu não (NMN) cao hơn so với chảy máu não $(\mathrm{CMN})$. Tỷ lệ tăng glucose, HbAc liên quan không có ý nghĩa với chẩn đoán ĐТĐ. Kết luận: Tăng glucose, $\mathrm{HbA1c}$ ở BN ĐQN giai đoạn cấp gặp với tỷ lệ cao, trong đó tăng glucose máu phản ứng độc lập so với ĐTĐ trước khi xảy ra đột quy.

Tù khóa: Đột quỵ não, nhồi máu não, chảy máu não, đái tháo đưòng, tăng glucose máu phản ứng.

Chịu trách nhiệm chính: Hoàng Trung Vinh

Ngày nhận bài: 02/11/2020

Ngày phản biện khoa học: 08/12/2020

Ngày duyệt bài: 29/01/2021

Email: hoangvinh.hvqy@gmail.com

Điện thoại: 0903201250

\section{1. ĐẠTT VẤN ĐỀ}

Đột quỵ não là biến cố cấp tính, nguy hiểm gặp với tỷ lệ cao, gây tử vong và tàn phế. Trong 
giai đoạn cấp của $\mathrm{DQN}$, cơ thể người bệnh xảy ra rất nhiều biến đổi ở các cơ quan và tổ chức, rối loạn nhiều quá trình chuyển hóa. Đây và là cơ chế thích nghi, bù trừ của cơ thể đồng thời không ít biến đổi trở thành biểu hiện bệnh lý, ảnh hưởng đến tiến triển của bệnh. Trong số các biến đổi theo cả hai khía cạnh thì rối loạn chuyển hóa carbohydrat là một trong những biến đổi hay gặp và rõ nét nhất. Biến đổi nồng độ glucose máu do nhiều nguyên nhân gây ra trong đó có phản ứng rối loạn hệ thần kinh - nội tiết. Đây là cơ chế quan trọng nhất. Biến đổi nồng độ glucose máu xảy ra ở cả BN ĐTĐ và không ĐTĐ, là yếu tố nguy cơ ảnh hưởng đến diễn biến, tiên lượng của bệnh. Phát hiện biến đổi nồng độ glucose, HbAic ở BN ĐQN giai đoạn cấp cần thiết cho thực hành lâm sàng và tiên lượng. Đề tài nghiên cứu nhằm mục tiêu: Khảo sát nồng độ glucose, $\mathrm{HbA1c}$ máu tại thời điểm nhập viện và mối liên quan với một số đặc điểm lâm sàng, cận lâm sàng ở bệnh nhân đột quỵ não (BN ĐQN) giai đoạn cấp tính điều trị tại bệnh viện Trưng Vương, TP Hồ Chí Minh.

\section{2. ĐỐI TƯợNG VÀ PHƯƠNG PHÁP}

2.1. Đối tượng: $98 \mathrm{BN} Đ Q N$ giai đoạn cấp tính điều trị nội trú tại bệnh viện Trưng Vương TP Hồ Chí Minh thuộc đối tượng nghiên cứu.

\subsubsection{Tiêu chuẩn lựa chọn}

+ Bệnh nhân được chẩn đoán ĐQN cấp tính.

+ Bao gồm cả nhồi máu não hoặc chảy máu não.

+ Thời gian nhập viện khác nhau kể từ khi xuất hiện triệu chứng của bệnh.

+ Đột quị não được xác định theo tiêu chuẩn của Tổ chức $\mathrm{Y}$ tế Thế giới.

+ Tiêu chuẩn chẩn đoán hình ảnh ĐQN trên chụp cắt lớp vi tính sọ não.

+ Đột quị lần đầu hoặc tái phát.

+ Bệnh nhân được hoặc chưa chẩn đoán bệnh ĐTĐ trước khi đột quị.

+ Đã hoặc chưa được điều trị trước khi nhập viện.

+ Bệnh nhân và/hoặc gia đình đồng ý tham gia nghiên cứu.

\subsubsection{Tiêu chuẩn loại trù̀ đối tự̆ng}

+ Đột quị do phình mạch hoặc dị dạng thông động - tĩnh mạch não.

+ Bệnh nhân u não.

+ Có tiền sử chấn thương sọ não.

+ Đã được truyền dung dịch huyết thanh ngọt trước khi đưa vào nghiên cứu.

+ Đã được sử dụng các thuốc điều trị ĐTĐ cả thuốc uống hoặc tiêm.

+ Tử vong trong vòng 24 giờ kể từ khi nhập viện.

+ Không thu thập đủ các chỉ số theo yêu cầu của nghiên cứu nhất là glucose máu tĩnh mạch, HbAlc.

\subsection{Phương pháp nghiên cứu}

Thiết kế nghiên cứu: tiến cứu, quan sát, cắt ngang.

\subsubsection{Nội dung nghiên cứu}

+ Khai thác bệnh sử.

+ Khám lâm sàng tại thời điểm $\mathrm{BN}$ nhập viện.

+ Thực hiện các xét nghiệm chẩn đoán (chụp cắt lớp vi tính sọ não - CT hoặc MRI), định lượng glucsoe, HbAlc.

\subsubsection{Tiêu chuẩn chẩn đoán, phân loại sử} dụng trong nghiên cứu.

+ Chẩn đoán $Đ Q N$ và thể đột quỵ theo tiêu chuẩn của tổ chức $\mathrm{Y}$ tế Thế Giới.

+ Đánh giá rối loạn ý thức theo thang điểm Glassgow.

Bảng 2.1. Tình trạng glucose máu ở bệnh nhân đột quỵ não cấp [80]

\begin{tabular}{|l|c|c|}
\hline \multicolumn{1}{|c|}{ Biểu hiện } & $\begin{array}{c}\text { Glucose máu lúc } \\
\text { nhập viện }\end{array}$ & $\begin{array}{c}\text { HbA1c } \\
\text { lúc nhập viện }\end{array}$ \\
\hline Tăng glucose máu phản ứng & Tăng & Bình thường \\
\hline $\begin{array}{l}\text { Rối loạn dung nạp glucose/ĐTĐ kết hợp với tăng } \\
\text { glucose máu phản ứng }\end{array}$ & Tăng & Tăng \\
\hline $\begin{array}{l}\text { Rói loạn dung nạp glucose/ĐTĐ không kèm theo } \\
\text { tăng glucose máu phản ưng }\end{array}$ & Bình thường & Tăng \\
\hline Không có tăng glucose máu phản ứng & Bình thường & Bình thường \\
\hline
\end{tabular}


Xác định tăng glucose máu ngẫu nhiên lúc nhập viện $>6,0$ mmol/1, HbAlc $\geq 5,7 \%$.

2.2.3. Xử lý số liệu và đạo đức y học trong nghiên cúu. lệ \%.

+ Xử lý số liệu bằng phần mềm SPSS 16.0 với việc xác định và so sánh giá trị trung bình, tỷ

+ Nghiên cứu không vi phạm đạo đức y học, không ảnh hưởng đến quá trình điều trị.

3. KẾT QUẢ NGHIÊN CÚ'U

Bảng 3.1. Tỷ lệ đối tượng theo nhóm tuổi và giới

\begin{tabular}{|l|c|c|}
\hline \multicolumn{1}{|c|}{ Tuổi (năm) } & Số lượng (n) & Tỷ lệ (\%) \\
\hline$<50$ & 11 & 11,2 \\
\hline $50-60$ & 22 & 22,4 \\
\hline $61-70$ & 38 & 38,8 \\
\hline $71-80$ & 17 & 17,3 \\
\hline$>80$ & 10 & 10,2 \\
\hline Nam & 42 & 42,9 \\
\hline Nữ & 56 & 57,1 \\
\hline Trung bình & \multicolumn{2}{|c|}{$84,03 \pm 19,39$} \\
\hline
\end{tabular}

+ Bệnh nhân thuộc các lứa tuổi khác nhau

+ Tuổi thấp nhất 33, cao nhất 90 .

+ Nhóm tuổi 61-70 chiếm tỷ lệ cao nhất

+ Lứa tuổi $>80$ chiếm tỷ lệ thấp nhất

+ Bệnh nhân nữ nhiều hơn so với bệnh nhân nam.

Bảng 3.2. Thể đột quỵ não của bệnh nhân

\begin{tabular}{|l|c|c|}
\hline \multicolumn{1}{|c|}{ Thể ĐQN } & Số lượng (n) & Tỷ lệ (\%) \\
\hline Nhồi máu não & 77 & 78,6 \\
\hline Chảy máu não & 11 & 11,2 \\
\hline Theo dõi nhồi máu não & 10 & 10,2 \\
\hline
\end{tabular}

+ Đa số bệnh nhân đột quỵ nhồi máu não.

+ Có $10,2 \%$ trường hợp được chẩn đoán theo dõi nhồi máu não.

Bảng 3.3. Tỷ lệ bệnh nhân dựa vào mức glucose

\begin{tabular}{|l|c|c|}
\hline \multicolumn{1}{|c|}{ Glucose (mmol/l) } & Số lượng (n) & Tỷ lệ (\%) \\
\hline$<5,6$ & 11 & 11,2 \\
\hline $5,6-6,0$ & 4 & 4,1 \\
\hline $6,1-7,0$ & 14 & 14,3 \\
\hline$>7,0$ & 69 & 70,4 \\
\hline Tồng cộng & 98 & 100,0 \\
\hline
\end{tabular}

+ Bệnh nhân với gluocse $>7,0 \mathrm{mmol} / \mathrm{l}$ chiếm tỷ lệ cao nhất.

+ Glucose máu từ 5,6-6,0 mmol/1 chiếm tỷ lệ thấp nhất.

Bảng 3.4. Tỷ lệ bệnh nhân dựa vào mức HbAlc

\begin{tabular}{|l|c|c|}
\hline \multicolumn{1}{|c|}{ HbA1c (\%) } & Số lượng (n) & Tỷ lệ (\%) \\
\hline$<5,7$ & 20 & 20,4 \\
\hline $5,7-6,4$ & 31 & 31,6 \\
\hline $6,5-7,0$ & 11 & 11,2 \\
\hline$>7,0$ & 36 & 36,7 \\
\hline Tồng cộng & 98 & 100,0 \\
\hline
\end{tabular}


$+\mathrm{HbA} 1 \mathrm{c}>7,0$ chiếm tỷ lệ cao nhất.

+ Bệnh nhân có HbAlc 6,5-7,0 chiếm tỷ lệ thấp nhất.

Bảng 3.5. Tỷ lệ bệnh nhân dựa vào biến đổi glucose trong đột quỵ não cấp.

\begin{tabular}{|l|c|c|}
\hline \multicolumn{1}{|c|}{ Biểu hiện } & Số lượng (n) & Tỷ lệ (\%) \\
\hline Tăng glucose máu phản ứng & 5 & 5,1 \\
\hline RLDNG/ĐTĐ kết hợp tăng glucose máu phản ứng & 15 & 15,3 \\
\hline $\begin{array}{l}\text { RLDNG/ĐTĐ kết hợp tăng glucose máu phản ứng không } \\
\text { kèm theo tăng glucose máu phản ứng }\end{array}$ & 10 & 10,2 \\
\hline Không có tăng glucose máu phản ứng & 68 & 69,4 \\
\hline Tổng cộng & 98 & 100,0 \\
\hline
\end{tabular}

+ Bệnh nhân có gluocse máu bình thường chiếm tỷ lệ cao nhất.

+ Tăng glucose máu phản ứng đơn độc chiếm tỷ lệ thấp nhất.

+ Tăng glucose máu phản ứng đơn độc hoặc phối hợp tương ứng 20,4\%

Bảng 3.6. Liên quan glucose máu với giới

\begin{tabular}{|c|c|c|c|c|c|}
\hline \multirow{2}{*}{ Glucose máu (mmol/l) } & \multicolumn{2}{|c|}{ Nứ } & \multicolumn{2}{|c|}{ Nam } & \multirow{2}{*}{$\mathbf{p}, \mathrm{OR}$} \\
\hline & $\mathbf{n}$ & $\%$ & $\mathbf{n}$ & $\%$ & \\
\hline$\leq 7(n=29)$ & 10 & 34,5 & 19 & 65,5 & $\mathrm{p}=0,004$ \\
\hline$>7(n=69)$ & 46 & 66,7 & 23 & 33,3 & $\mathrm{OR}=8,65$ \\
\hline Tổng cộng & 56 & 100 & 42 & 100 & \\
\hline
\end{tabular}

+ BN nữ có glucose máu $>7 \mathrm{mmol} / 1$ cao hơn so với bệnh nhân nam.

+ BN nam có glucose máu $\leq 7 \mathrm{mmol} / 1$ cao hơn so với bệnh nhân nữ.

+ Sự khác biệt có ý nghĩa thống kê với $\mathrm{p}=0,004, \mathrm{OR}=8,65$.

Bảng 3.7. Liên quan giữa glucose máu với thể đột quỵ não

\begin{tabular}{|c|c|c|c|c|c|}
\hline \multirow{2}{*}{ Glucose máu (mmol/l) } & \multicolumn{2}{|c|}{ NMN } & \multicolumn{2}{|c|}{ CMN } & \multirow[b]{2}{*}{$\mathbf{p}$} \\
\hline & $\mathbf{n}$ & $\%$ & $\mathrm{n}$ & $\%$ & \\
\hline$\leq 7(n=29)$ & 25 & 86,2 & 4 & 13,8 & $\mathrm{p}=0,763$ \\
\hline$>7(n=69)$ & 61 & 88,4 & 8 & 11,6 & \\
\hline Tổng cộng & 86 & 87,8 & 12 & 12,2 & \\
\hline
\end{tabular}

Mức glucose máu liên quan không có ý nghĩa với thể đột quỵ não.

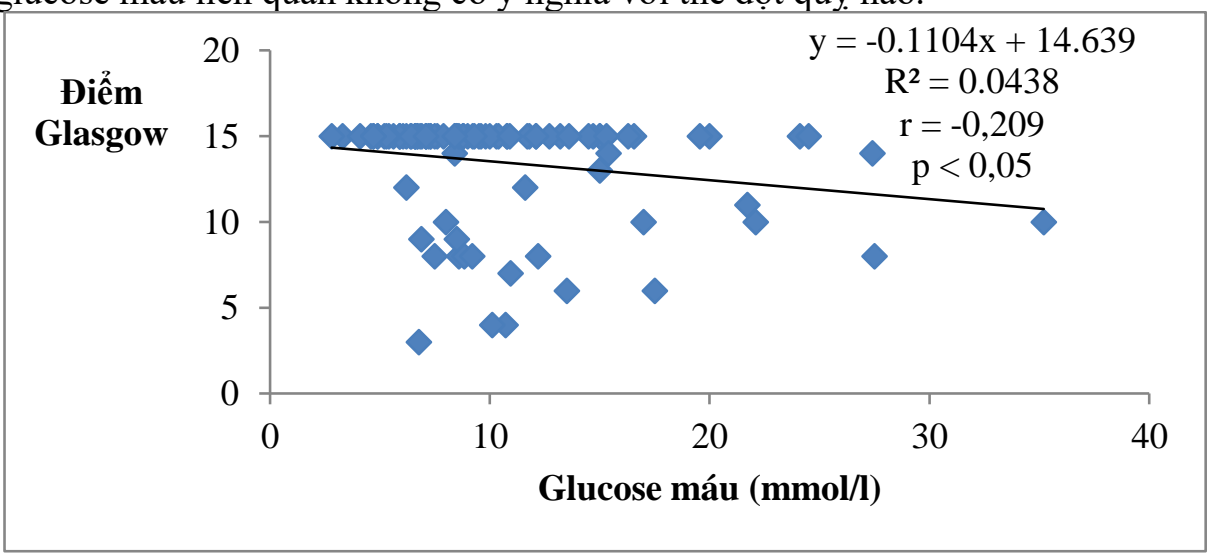

Đồ thị 2.1. Liên quan giữa glucose máu với điểm Glassgow 
Nồng độ glucose máu tương quan nghịch với điểm Glassgow ( $<<0,05 ; \mathrm{r}=-0,209)$.

Bảng 3.8. Liên quan $\mathrm{HbAlc}$ với thể đột quỵ não

\begin{tabular}{|c|c|c|c|c|c|}
\hline \multirow{2}{*}{ HbA1c (\%) } & \multicolumn{2}{|c|}{ NMN } & \multicolumn{2}{|c|}{ CMN } & \multirow[b]{2}{*}{$\mathbf{p}$} \\
\hline & $\mathbf{n}$ & $\%$ & $\mathbf{n}$ & $\%$ & \\
\hline$<6,5(\mathrm{n}=51)$ & 41 & 80,4 & 10 & 19,6 & $\mathrm{p}=0,029$ \\
\hline$\geq 6,5(n=47)$ & 45 & 95,7 & 2 & 4,3 & $\mathrm{OR}=5,85$ \\
\hline Tổng cộng & 86 & 87,8 & 12 & 12,2 & \\
\hline
\end{tabular}

Bệnh nhân nhồi máu não có tỷ lệ $\mathrm{HbA1c} \geq 6,5 \%$ cao hơn so với bệnh nhân chảy máu não $(\mathrm{p}=0,029, \mathrm{OR}=5,85)$.

\section{BÀN LUẬN}

Kết quả khảo sát cho thấy trong số BN nghiên cứu thì số trường hợp tăng glucose máu chiếm tỷ lệ rất cao. Nếu tính cả mức tăng glucose máu giới hạn và mức tăng thực tế thì tỷ lệ lên đến $89,9 \%$; chỉ có $11,2 \%$ trường hợp glucose máu $<5,6 \mathrm{mmol} / 1$. Đây là một tỷ lệ khá cao. Tăng glucose máu ở đột quỵ não giai đoạn cấp có thể do bệnh hoặc stress. Đây cũng được coi là một trong các cơ chế tích nghi, bù trừ của cơ thể [1]. Nhiều tác giả cũng nhấn mạnh rằng bản thân đột quỵ não giai đoạn cấp tính cũng có những biểu hiện kháng insulin, giảm độ nhạy insulin và giảm chức năng tế bào $\beta$. Đây là các YTNC độc lập với đột quỵ não kể cả khi kiểm soát glucose máu đạt yêu cầu [2], [3]. Kernan WN và cs năm 2005 nhận thấy $B N$ đột quỵ não thể nhồi máu kể cả cơn thiếu máu não thoáng qua có $28 \%$ giảm dung nạp glucose; $24 \%$ đái tháo đường. Nếu trước khi xuất hiện đột quỵ não mà $\mathrm{BN}$ có nồng độ glucose máu $\geq$ $6,1 \mathrm{mmol} / 1$ sẽ là YTNC cao rối loạn dung nạp glucose và đái tháo đường sau đó [4]. Mazighi M và cs năm 2001 nhận thấy tăng glucose máu gặp ở trên $50 \%$ trường hợp đột quỵ não cấp, là yếu tố tiên lượng xấu cho tử vong và hồi phục tổn thương thần kinh. Nếu nồng độ glucose $>$ $8 \mathrm{mmol} / 1$ thì cần cân nhắc sử dụng insulin [5]. Mặc dù đối tượng trong nghiên cứu này có $92,9 \%$ đã xác định đái tháo đường trước khi đột quỵ não xảy ra, có thể đa số trước đó đã được điều trị song tỷ lệ đối tượng tăng glucose máu đặc biệt ở mức $>7,0 \mathrm{mmol} / 1$ chiếm tỷ lệ cao lên đến $70,4 \%$.

Khác với sự biến đổi glucose, ở BN đột quy não giai đoạn cấp nhận thấy cũng có biển đồi HbA1c. Tuy vậy nếu tính tăng HbAlc khi >
6,5\% thì tỷ lệ đó ở đối tượng nghiên cứu gặp $47,9 \%$ thấp hơn so với mức bình thường $(\mathrm{HbA} 1 \mathrm{c}<6,5 \%)$. Sự khác biệt giữa tỷ lệ tăng glucose và $\mathrm{HbA} 1 \mathrm{c}$ cho thấy rõ ràng có phản ứng tăng glucose máu của cơ thể trong pha cấp của đột quỵ não. Nếu tính chung mức tăng glucose và $\mathrm{HbA} 1 \mathrm{c}$ đều trên 7 đơn vị thì glucose tăng chiếm tỷ lệ cao hơn so với tăng $\mathrm{HbA} 1 \mathrm{c}$ (70,4\% so với $36,7 \%)$. Van $\mathrm{KH}$ và cs khảo sát BN đột quỵ não trong pha cấp nhận thấy có $43 \%$ tăng glucose máu trong đó $55 \%$ hoặc đã được chẩn đoán đái tháo đường hoặc đái tháo đường tiềm tàng [6].

Khi phân tích mối liên quan giữa biến đổi nồng độ glucose, HbA1c với giới nhận thây: BN nữ bị đột quỵ não có tỷ lệ tăng glucose phản ứng ở mức $>7 \mathrm{mmol} / 1$ chiếm cao hơn có ý nghĩa so với $\mathrm{BN}$ nam, với $\mathrm{p}=0,004$, $\mathrm{OR}=8,65$. Có lẽ với cách quan sát bệnh nhân như trong đề tài thì còn khó để giải thích vì sao biến đổi glucose máu liên quan với giới. Tương tự nếu lựa chọn $\mathrm{HbA} 1 \mathrm{c} \geq 6,5 \%$ là mức tăng thì nhìn vào kết quả phân tích cũng nhận thấy bệnh nhân nữ có tỷ lệ tăng HbAlc cao hơn có ý nghĩa so với bệnh nhân nam, với $\mathrm{p}<0,05$, $\mathrm{OR}=3,6$. Như vậy thấy rằng cả mức tăng glucose và $\mathrm{HbA1c}$ thì ở $\mathrm{BN}$ nữ đều gặp với tỷ lệ cao hơn so với $\mathrm{BN}$ nam.

Chỉ có một số tác giả nêu ra kết quả về tần suất đột quỵ não ở nam và nữ có sự khác nhau song cũng chưa có tác giả nào khẳng định giới nam hoặc nữ là YTNC của đột quỵ não. Giới có thể liên quan có ý nghĩa với rối loạn glucose máu nói chung và đái tháo đường typ 2 nói riêng. Chưa thấy tác giả nào nêu nên kết quả về mối liên quan có ý nghĩa giữa biến đổi glucose máu với giới ở BN đột quỵ não giai 
đoạn cấp. Có thể mối liên quan giữa tăng glucose máu với giới là do số lượng $\mathrm{BN}$ nữ mắc đột quỵ não nói chung cao hơn và cũng có thể đái tháo đường trước khi xảy ra đột quỵ não cũng cao hơn.

Tỷ lệ đái tháo đường typ 2 ở $\mathrm{BN}$ đột quỵ não thể nhồi máu não và chảy máu não cũng không có sự khác nhau. Khi phân tích tỷ lệ Bn dựa vào mức glucose máu ở $\mathrm{BN}$ nhồi máu não hoặc chảy máu não nhận thấy đều khác biệt không có ý nghĩa thống kê. Như vậy thấy rằng tỷ lệ tăng glucose máu liên quan chưa có ý nghĩa với thể đột quỵ não.

Khi phân tích mối tương quan giữa nồng độ và glucose máu với điểm Glassgow nhận thấy đây là mối tương quan nghịch có ý nghĩa, tương quan mức độ ít. Khi ý thức $\mathrm{BN}$ càng kém thì mức độ tăng glucose máu càng cao. Cũng có thể một phần nào tăng glucose máu góp phần làm ý thức của $\mathrm{BN}$ xấu đi. Điểm Glassgow là yếu tố tiên lượng có ý nghĩa đối với đột quỵ não.

Qua kết quả trên cũng có thể nói tăng glucose máu góp phần hoặc là một yếu tố thêm vào đối với tiên lượng của đột quỵ não. Weshahy $A$ và cs năm 2017 có nhận xét nếu BN đột quỵ não có tăng glucose máu thì khi mức độ tăng glucose máu càng cao thì kết cục lâm sàng càng xấu hơn, mức độ bệnh nặng hơn, tỷ lệ tử vong cao hơn, thời gian nằm viện cũng dài hơn. Điểm cắt glucose $\geq 223 \mathrm{mg} / \mathrm{dl}$ là yếu tố tiên lượng xấu đối với người bệnh [7].

\section{KẾT LUÂN}

Qua nghiên cứu trên 98 bệnh nhân đột quỵ não giai đoạn cấp tính điều trị nội trú tại bệnh viện Trưng Vương TP Hồ Chí Minh, chúng tôi có một sso nhận xét sau:

- Tăng glucose và $\mathrm{HbAlc}$ chiếm tỷ lệ cao (glucose máu $>6,0 \mathrm{mmol} / 1-84,7 \%$; HbAlc $\geq$ 5,7-89,6\%).

- Tỷ lệ tăng glucose máu phản ứng đơn độc hoặc phối hợp gặp 20,4\%.

- Tỷ lệ tăng glucose, HbA1c cũng như tăng glucose máu phản ứng liên quan không có ý nghĩa với đái tháo đường đã được chẩn đoán trước khi đột quỵ não.

- Bệnh nhân nữ có tỷ lệ tăng glucose, HbA1c cao hơn có ý nghĩa so với bệnh nhân nam.

- Nồng độ glucose tương quan nghịch có ý nghĩa với điểm Glassgow.

- Nhồi máu não có tỷ lệ tăng $\mathrm{HbA} 1 \mathrm{c} \geq 6,5 \%$ cao hơn so với chảy máu não.

- Nồng độ glucose máu liên quan chưa có ý nghĩa với tuổi, thể đột quỵ não. HbAlc liên quan chưa có ý nghĩa với tuổi, điểm Glassgow.

\section{TÀI LIỆU THAM KHẢO}

1. Nguyễn Văn Ngọc (2008). Nghiên cứu nồng độ glucose máu và kháng insulin ở bệnh nhân đột quy não giai đoạn cấp tính. Luận văn tốt nghiệp bác sĩ chuyên khoa cấp II, Học viện Quân y.

2. Hoàng Trung Vinh, Nguyễn Văn Ngọc (2010). Kháng insulin và chức năng tế bào $\beta$ ở bệnh nhân đột quỵ não giai đoạn cấp tính. Tạp chí Y - Dược học Quân sự số 1, tr.73-78.

3. Bravata DM, Wells CK, Kernan WN, et al. (2005) "Association between impaired insulin sensitivity and stroke", Neuroepidemiology, 25(2), pp.69-74.

4. Kernan WN, Viscoli CM, Inzucchi SE, et al. (2005) " Prevalence of abnormal glucose tolerance following a transient ischemic attack or ischemic stroke". Arch Intern Med, 165(2), pp.227-233.

5. Mazighi $M$, Amarenco $P$ (2001). "Hyperglycemia: a predictor of poor prognosis in acute stroke". Diabetes Metab, 27(6), pp.718-720.

6. Van KF, Hoogerbrugge N, et al. (1993) " Hyperglycemia in the acute phase of stroke is not caused by stress". Stroke, 24(8),pp.1129-1132.

7. Weshahy A, Sherif R, et al. (2017) "Short term outcome of patients with hyperglycemia and acute stroke". The Egyptian Journal of Critical Care Madicine, pp.93-98. 